\title{
The Portrayal of "Foreigners" in Japanese Social Studies Textbooks: Self-Images of Mono-Ethnic Pluralism
}

\author{
TSUNEYOSHI, Ryoko*
}

\begin{abstract}
History and social studies textbooks have often been the object of heated political debate in various countries, since they relate directly to issues of national identity and citizenship. This article analyzes how "foreigners" are portrayed in two versions (the 2000 and 2006 versions, date of issue) of the best-selling elementary social studies textbook in Japan. How "foreigners" are portrayed, reflects how non-foreigners, in other words, "Japanese," are understood. The study categorized the sections containing key terms and themes that were relevant to foreign/foreigners (see article for exact list). Based on a content analysis, the results were broken down into 8 themes (plus "Other"), and their patterns were analyzed. The major findings were that (1) despite the image of Japanese as having a monocultural image of themselves, the image of ethnic Japanese and Japanese society in the textbooks was actually very diverse in terms of region, climate, landscape, occupation, etc.; (2) images of coexistence were also present, but the objects of coexistence were dominantly of two kinds-first, the coexistence of Japanese with nature, and second, the coexistence of Japan with foreign countries through trade; and (3) in cases that the "foreigners" did appear in the textbooks, the image shifted according to the context in which it was discussed, and there was a missing link between the different meanings. In other words, when the context was contemporary Japan $\left(3^{\text {rd }}-5^{\text {th }}\right.$ grade), "foreigners" were portrayed as visitors who came and left, and the key concept was "internationalization." When "foreigners" were discussed historically (first half of $6^{\text {th }}$ grade), or were discussed in relation to welfare, peace, human rights and discrimination, they were assumed to be the permanently residing foreigners in Japan (the Koreans and Chinese in Japan). The article analyzes the implications these findings have for a more multicultural and pluralistic Japanese self-image.
\end{abstract}

\section{Introduction}

Education related to values, whether it is moral education, religious education, character education or citizenship education, is experiencing a revival in many countries around the globe.

\footnotetext{
* The University of Tokyo

e-mail: tsuney@educhan.p.u-tokyo.ac.jp
} 
In the United Kingdom, "citizenship" became statutory from August 2002 in the national curriculum for key stage 3 (year 11-14) and key stage 4 (14-16) ${ }^{1}$. Major associations in the United States (e. g., Center for Civic Studies) and the EU (e. g., Council of Europe) are issuing statements and curriculum material on citizenship ${ }^{2}$. In Asia as well, there have been indications of a revival of values education (Cummings et al. eds., 1989; 2001), and in the Japanese case, various organizations including the government (Keizai Sangyosho, 2006), schools and districts (Shakaikakyoiku 2005; Shinagawaku Kyoikuiinkai 2006) have started to join the citizenship movement. A revival of moral education, called the "education of the heart" (kokoro no kyoiku) is also underway. There has also been an ongoing history textbook war which focuses on reinterpreting the role Japan played in the last World War (Nishio 2001; Fujioka 2005).

This study will focus on one aspect of values education in Japan, which is how "foreigners" are portrayed in Japanese elementary social studies textbooks. How "foreigners" are portrayed is closely related to how "Japanese" - whoever that may be - are understood. This has implications for where the boundaries of the society are being drawn in the minds of the majority Japanese (Tsuneyoshi 2003).

It should be mentioned here that "foreigners" in Japan are often the counterpart of ethnic minorities in other countries. Unlike in societies where immigrants are assumed to become future citizens/nationals, Japanese nationality is either gained through one's Japanese parents, or through naturalization. Japan colonized Korea in 1910, and many Koreans came to Japan either voluntarily, or by force. After the defeat of Japan, many Koreans were led to remain in Japan, but were deprived of their Japanese nationality. This has led to a situation where there are many Koreans in Japan who have been in Japan for generations, speak Japanese in daily life, and are indistinguishable from the majority on the surface. Kajita $(1998,131)$ refers to such individuals as being "sociologically Japanese," but not having Japanese nationality. In recent years the situation of the Koreans in Japan has diversified. There are more Koreans who have naturalized, thus they are Japanese nationals but are ethnically Korean. Children born between a Korean and Japanese couple acquire Japanese nationality, thus, are ethnically partly Korean but also are Japanese nationals. A similar situation has existed for a number of Chinese. There is also an inflow of guest workers and other new types of foreigners since the 1980s. Given the diversity of the "foreign" situation in Japan, how "foreigners" are portrayed within Japanese society inevitably brings up issues of equity, power, and the self-image of a nation.

Through a content analysis of Japanese elementary social studies textbooks, this study examines how "foreigners" are portrayed. This analysis not only coded themes related to "foreigners", but also more widely to internationalization, coexistence, etc. in order to better uncover the latent logic explaining "foreigners" (cf. methods section).

Analysis of textbooks in other countries has revealed biases in the portrayal of ethnic minorities and women, and textbooks have often become targets of ideological struggle (FitzGerald 1979; Altbach et al. eds. 1991). History and social studies textbooks have been prime targets of political struggle, since how a nation portrays its past is related to how it interprets its present and future. One could be a part of a society, and even have legal status within it, without being recognized in the textbooks (e. g., as is the case of the role of minorities largely forgotten in the descriptions of history textbooks), or one could be portrayed misleadingly.

In immigrant countries such as the United States, the center of the history/social studies textbook wars has often been the portrayal of minorities/women. On the other hand, the most heated debates over Japanese history/social studies textbooks have been over the portrayal of Japan's 
aggression to Asia during World War II (Nash et al., 1997; Nishio 2001; Fujioka 2005; Ienaga Kyokasho Sosho Bengodan 1998 ). The content of these history wars is not the topic of this article. However, it is important to keep in mind that examining how "foreigners" are portrayed, not just minorities, is especially important in the Japanese case, since "foreigners" include what would be ethnic minorities in other societies. The Koreans in Japan are the prime example.

Before analyzing the textbooks, a brief comment on the situation of the "foreigners" in Japan will be provided to place the textbooks in context.

\section{The "Foreigners"}

As opposed to societies where ethnicity/race is a central concern of politics, and identity politics flourish, ethnicity and race tend not to be central political issues which challenge the majority dominance in Japan. This is reflected in the textbooks. For example, elementary school textbooks in Singapore are similar to Japanese textbooks in that they contain only the core essence of the subject and are thus very thin. However, they differ from their Japanese counterparts in that the pictures of children drawn on the pages are consciously from the three major ethnic groups, Chinese, Malay, and Indian. As the concern over gender equality has risen in Japan, there is a conscious representation of both genders in the textbooks. However, racially, all children in the textbooks look "Japanese." Whether they are, of course, there is no way of knowing by just looking at the pictures, since one could easily say that they are Chinese or Korean. As will be seen later, however, there is very little awareness of people of different cultures in the Japanese textbooks, therefore, it is doubtful that any of the illustrations of children are intented to be ethnic minorities.

Though the term "foreigners" (gaikokujin) is commonly used to identify the culturally different in Japan, there are different types of foreigners. First, there are the colonized populations. The Koreans in Japan are the representative examples of this category, and members of this category are conventionally called the oldcomers, as compared with the new foreigners who are called the newcomers. From the late 1970s onward, especially after the revisions to the Immigration Control and Refugee Recognition Law in 1990, the number of the Latin Americans of Japanese descent increased. There were others who came as spouses of Japanese, Indochinese refugees, or Chinese returnees, or who came to Japan as students, or were businesspersons stationed in Japan. These foreigners came to Japan under very different conditions and reasons compared to the Koreans and Chinese who came because of Japan's colonial rule. Registered foreigners constituted $1.57 \%$ of Japan's population $(2,011,555)$ as of the end of $2005^{3}$. This does not include ethnic Japanese or those without legal status.

The 1980s also marked the era of growing international competition, and "internationalization" became a commonplace word in both the media and in academia. Although the awareness of diversity within Japanese society has grown, the situation is quite different from countries where identity politics thrive and ethnicity and race are central issues of equality of educational opportunity. Discussions of ethnicity, nationality and equity is limited. Ethnicity is a political issue mainly in certain districts where there is a concentration of foreigners/ethnic minorities (Tsuneyoshi 2004), and the major politicized issue in relation to ethnicity and nationality in social studies is the portrayal of Japanese military aggression to Asia (especially China and Korea) during the WWII. Such is the state of "foreigners" which provides the background against which textbooks are writ- 
ten.

\section{3 "Foreigners" in Japanese Social Studies Textbooks}

\section{Social Studies Textbooks}

Textbooks are one indicator of what education in a country aims to transmit to childrenthough this transmission may not necessarily take place. This section examines the message Japanese elementary school social studies textbooks are sending to Japanese society by analyzing how "foreigners" are portrayed.

Japanese textbook revisions are affected by the changes in the national curriculum standards. When a shift in emphasis occurs in the contents of the Course of Study, a corresponding shift occurs in the textbooks. For example, the Course of Study and the governmental committees have increasingly emphasized communication (vs. grammar) in secondary school foreign language (English). Thus, textbooks by various publishers, responding to the shift, have emphasized more conversation and communication in its revisions. A parallel shift in social studies has been the call for more child-relevant learning, including going out into the community, more emphasis on investigating, writing up and presenting rather than the "passive remote memorization" of knowledge that was seen as characteristic of previous social studies learning.

This study focuses on an analysis of the 2000, and the most recent 2006 (issued date, not approved date; approved dates are 1999 and 2004) revised versions of the elementary school social studies textbook from A publisher with more than half the market share. The textbook company with the second largest share was also analyzed for comparison (2000 version only).

\section{Method}

The subject of social studies is taught from third grade onward. This is because at the first and second grade level, social studies and science are combined under the label of Life Sciences (seikatsuka). Textbooks for 3-6 $6^{\text {th }}$ grade from A textbook publisher for the 2000 and 2006 revised versions were reviewed word by word for any descriptions or pictures relating to the following key terms and themes: "coexistence" (kyosei), including coexistence with nature, coexistence with the international community, etc., "foreign" (gaikoku), including foreign countries, foreign trade, foreign culture, foreigners, etc., "minorities" (references to ethnic minorities, people with handicaps, the elderly, women; and any other minority), "overseas" or the "world" (kaigai, sekai), "international/internationalization/global/globalization" (kokusai, kokusaika, gurobaru, gurobaruka).

Based on this process, the following codes were formulated: (1) "Foreigners as Transient Visitors," (2) "International Linkages Via Commodities" (including a sub-code on trade friction), (3) "Examples of Foreign Countries Used as a Reference to Understand Japan," (4) "Special Issues" (consisting of the U. S. military in Japan and the northern territories, because these issues are dealt with in a different manner from the rest of the topics), (5) "International Assistance, International Exchange, International Cooperation and Understanding Other Cultures" that consists mostly of descriptions of contributions made by Japan and the Japanese to the world, (6) "International Linkages Via Information," (7) "Coexisting with Nature," (8) "People with Handicaps, Women, Elderly, Ethnicity," and (9) "Other." 


\section{Results}

\section{General Trend}

Both the 2000 and 2006 textbook editions reflect the trend towards a more child-relevant curriculum. The increasing emphasis on thinking skills, activities such as investigating and researching (e. g., using the Internet to gather material, going to the library), going out into the community (e. g., visit museums and related facilities, interviewing), discussion in small groups, expressing views and opinions (e. g., all of the textbooks contained many pictures of boys and girls expressing views and opinions alternately) and giving presentations appeared with high frequency. The implication here is that these abilities are being promoted intentionally as important qualities for the next generation of Japanese. This tendency is more systematically advanced in the 2006 version, which contains sections on "how to learn" (three target areas being, investigating, bringing together, and communicating).

The basic structure in which the textbooks proceed from grade to grade first focuses on the local area where the child resides, to the larger Japan (3-5 $5^{\text {th }}$ grade), and from it to the world ( $6^{\text {th }}$ grade civics). The first half of $6^{\text {th }}$ grade is history, the latter half is civics. In junior high, social studies is divided into three areas-history, geography, and civics.

An analysis of the codes from $3^{\text {rd }}$ to $5^{\text {th }}$ grade reveals two axes of difference which the textbooks use to portray diversity in Japan. The first is the axis that attempts to capture the internal diversity of Japan in terms of climate, landforms, regions, and various ways of life (e. g., unit on "life in snow country"), different industries, and various occupations. This will be called the "Japan as pluralistic" axis. This axis tries to portray the diversity among Japanese in a balanced and comprehensive manner. Thus, if the snowy regions are covered, the tropic regions are also covered. Fishing, agriculture, industry, etc. are all portrayed in the same manner, as having equal worth. The textbooks are careful to show that people living in the snowy areas such as Niigata, have been just as resourceful in innovatively coping with their environment, in inventing their own local tradition, as have been people in the tropic areas, such as Okinawa. Here, the framework used to understand and balance these diverse groups is "getting to know Japan," in other words, familiarity with one's own country. The framework here is not multicultural in the sense that it recognizes differences in power, minority-majority differences, or conflict. The groups are all portrayed as equal, and the relationship is horizontal and takes as its unit the nation-state. The perspective here is pluralistic, but mono-ethnic and bound to the nation-state.

Though Japan is often accused of disregarding diversity, it is important to note here that in so far as the social studies textbooks are concerned, the "Japan as pluralistic" axis is actually a central perspective in the social studies textbooks. From $3^{\text {rd }}$ to $5^{\text {th }}$ grade, this message of Japan as pluralistic basically comprises the core content of the textbooks.

There is a second axis, however, which intersects with this "Japan as pluralistic" axis. Here, the key term is "coexistence" (kyosei), since there is a latent understanding of conflicting interests and the need to promote coexistence. The object of coexistence, however, as will be seen below, is most often nature, or foreign nations engaged in trade with Japan.

The interesting point when examining the "coexistence" axis is that the bulk of this category falls into just two codes, that of "Coexisting with Nature" and "International Linkages Via Commodities."

Table 1. is given as an indicator of how many units contain a key word/theme that relates to the code. The numbers are only indicators, since there may be some dispute over the codes, and 
since the word or theme may appear repeatedly in a unit but that will be counted once. But the numbers give one indicator of the frequency a certain word or theme appears by unit (total number of units from $3^{\text {rd }}-5^{\text {th }}$ grade, 2000 version, 39 units, 2006 version 27 units). More detailed content for certain key codes are provided in table 2.

Table 1. Number of Units a Category Appears by Textbook Version

\begin{tabular}{llcc}
\hline \multicolumn{1}{c}{ Category } & \multicolumn{1}{c}{ 2000 version } & 2006 version & TOTAL \\
\hline Coexisting with Nature & 24 plus back of cover & 16 & 40 \\
International Linkages Via Commodities & 17 & 13 & 30 \\
$\quad$ (of which focus on conflict & 7 & 2 & 9 ) \\
& & & \\
Examples of Foreign Countries & 11 & 3 & 14 \\
People with Handicaps, etc & 6 & 5 & 11 \\
International Assistance, etc. & 5 plus picture in glossary & 4 & 9 \\
Foreigners as Transient Visitors & 5 plus back of 2 covers & 3 & 8 \\
Special Issues & 3 & 1 & 4 \\
Int. Linkages Via Information & 1 & 2 & 3 \\
\hline
\end{tabular}

The "Special Issues" unit includes the US military in Okinawa and the northern islands in dispute with Russia. For the category "International Linkages Via Information," though the total numbers are low, the 2006 version has many more pages than the 2000 version which refer to how information technology links different nations-presumably reflecting an increasing awareness of the importance of information. The topics that appear under the code "People with Handicaps, Women, Elderly, Ethnicity" (permanently residing foreigners) are mostly either of the handicapped or the elderly which tend to go together.

From this, it can safely be said that "Coexisting with Nature" and "International Linkages Via Commodities" are the two main codes when discussing issues of "coexistence" at these grade levels. Above all, the "Coexistence with Nature" theme is central in the textbooks from grades 3 to 5, and this tendency was particularly prominent in the second best-selling publisher's textbooks, which contained fewer materials on foreign cultures compared to Publisher A in the 2000 version. In either case, the theme of coexistence between humans and nature permeates most of the descriptions on professions and regions in Japan. For example, in industry, the example given is the development of the hybrid car which is eco-friendly, fishermen maintain that they must not only catch fish but breed fish for sustainable fishing, and examples of NGOs and efforts by citizens to preserve nature appear repeatedly in different grades.

The other most prominent theme is "International Linkages Via Commodities," in other words, the message that the link between Japan and other nations is through commodities, mostly brought about through increasing trade with other countries. Children are portrayed as discovering that they have ties with the South East Asian countries or with China, when they go to the grocery shop and find bananas and other daily items from these countries. This image of coexistence with other countries, via trade, often assumes conflict, and there are descriptions here and there of trade conflict, of foreign goods pressuring Japanese products, and of the negative result of Japanese trade for the developing countries (e. g., the disappearance of rain forests in developing countries are linked to over-consumption in Japan).

Compared to these two overarching themes, other "coexistence" themes tend to be limited and concentrated in certain units. 
The grade levels that deal with contemporary issues is from grade 3-5, and the latter half of $6^{\text {th }}$ grade which is civics. This civic section also has a strong "Coexistence with Nature" message but not a trade message (rather "International Assistance, etc." becomes the major theme instead). Thus if we take grades 3-6 put together, it can safely be said that "Coexisting with Nature" is the central coexistence theme that cuts across all grades and units.

In comparison, when analyzing the grade 3-5 textbooks, almost all foreigners or people from different cultures that are portrayed can be categorized under "Foreigners as Transient Visitors" as can be seen in table 2. The foreigners portrayed here are assumed to come and go, and appear only in certain limited units or sub-units, and captions of pictures (cf. discussion in next section). Thus, to summarize at this point, the $3-5^{\text {th }}$ grade social studies textbooks send the message that there are a diversity of regions, occupations and Japanese people inside Japan who are each of equal worth, and in this sense, Japan is a highly pluralistic society. Coexistence with nature is important. There are also increasing links with other countries which are mostly portrayed

Table 2. Publisher A 2000 (Approved 1999) and 2006 (Approved 2004) Versions Elementary School Social Studies

Related Units Contents Page

\section{Sections that were classified under "Foreigners as Transient Visitors"}

(3 ${ }^{\text {rd }}$ Grade Part 1)

Back of cover: There is a picture of a white man and girl child as well as a woman in a wheel chair with the title, "I wonder whom I can meet?!"

\section{My Community, Everyone's Community}

Unit 2. Everyone Makes the Community "Everybody's Community Center" Photographs of people conversing in sign language and pictures of conversation with a foreigner (white) in English (3 ${ }^{\text {rd }}$ Grade Part 2)

4 Changing People's Lives

Unit 3 The Town I want to Live in, "Making People-Friendly Towns," Child's Face: "Pictograms that are also easy for foreigners to understand..." Shown together with children's views on barrier free environment (elderly, handicapped) (4th Grade Part 1)

Back of Cover: "Walk, Watch, Listen" Photographs of foreigners (various races) visiting the school

* Image of schools teaching international understanding, photographs of visiting foreigners and handshakes 2 Our Prefecture

"Friends with the World" Foreigners Visit Our School (the native countries are on a map)

Unit 2. "Snapshots of Prefectures and Life Style" "The World within Miyagi Prefecture" Reference to exchange students and in the margins, "How is our prefecture linked to foreign countries?"

(4 ${ }^{\text {th }}$ Grade Part 2)

4 Live in Various Regions and Our Country

Unit 3. Life in Warm Regions, Okinawa Prefecture, "Opening Up to Asia" * There were deep interchanges with China and other countries of Asia in the past. Shanghai and Taipei are located close to Naha."Many people still visit even now for sightseeing and business." We would like to continue to promote trade and deepen our interchange with Asia. Figure showing the location of Okinawa Prefecture (proximity to foreign countries) and visitors:

\section{Revised Version}

(3/4 Part 1)

6 Our Prefecture

Unit 4 The Prefecture and the Progress of Our Town * A Malaysian student makes comments

"Challenge" A foreign teacher comes from Pittsburgh, the sister city

$\left(5^{\text {th }}\right.$ Grade Part 1)

2 Our Life and Industrial Goods

Unit 3 Industry and Trade "Japan Within the World" * A comment from a Malaysian student

(5 ${ }^{\text {th }}$ Grade Part 2)

4 Our Land and Environment

Unit 2 Our Life and Environment "What we can do to preserve the environment" * Pictures of foreign children participating in the World Water Forum 
Sections categorized under "People with Handicaps. Women, the Elderly, Ethnicity (permanently residing foreigners)"

(3rd Grade Part 1)

1 My Community, Everyone's Community

Unit 2. Everyone Makes the Community "Everybody's Community Center" A photograph of children speaking in sign language is shown in the section on community center activities.

Unit 3. Investigating the City "The Secret to the Reason So Many People Come," a picture of elderly person in a wheelchair shopping

(3rd Grade Part 2)

* Elderly people appear in this $3^{\text {rd }}$ grade part 2 not from the perspective of welfare, but as someone who teaches the children about old tools and lifestyle.

4 Changing Lifestyles

Unit 3. The Town I Want to Live In, "Various Towns" * Foreign towns that are resident-friendly from the perspective of disabled people and others. * Included in "Advanced Materials for Books"

3. "Building a People-Friendly Town" Resident-friendly town-building from the perspectives of foreigners, people with handicaps (braille), the elderly, and animals * Included also in "Foreigners As Transient Visitors" and "Coexisting with Nature")

(4th Grade Part 1)

1 To Enable a Healthy and Safe Life

Unit 3. Protecting Against Fires "Let's Investigate Roads" Discussion on resident-friendly towns for the elderly and people with disabilities

(5th Grade Part 1)

2 Our Life and Industry

Unit 2. Auto-industry "Assembling Doors" A quote on improving the situation for women

(5th Grade Part 2)

Unit 6. "Living Together" By the Table of Contents - Elderly people and children

\section{Version}

(3/4 Grade Part 1)

2 Occupations and Our Life

Unit 1. People Who Work in Supermarkets, Who makes it easier for people in wheelchairs and the elderly to work? ${ }^{*}$ with picture

Same unit, With the People in the Community, a person with a sight-seeing dog, the mark of a wheelchair

Unit. 2. Training dogs for the visually challenged

3 Protecting Our Life

Unit 2. If Something Happens "Let's check out the roads" * picture of elderly and sign language

Unit 3. Towards a Town We can Live Safely "Planning Today's Towns" * child comments on roads that wheelchairs can pass

(Grade 5 Part 2)

4 Our Land and Environment

Unit 1. Various Forms of Nature and Our Lives

"Looking at Japan from Hokkaido" * Introduces the dance of Ainu

Also, "Looking at Japan from Okinawa" has a picture of Okinawan emigrants gathering in Japan

through trade, but there are also some portrayal of foreigners or people of other cultures inside Japan. However, these foreigners are assumed to be visitors, who come and go as a result of Japan's internationalization. Lacking is the portrayal of Japan's ethnic minorities and permanently residing foreigners. There is an awareness of the need for multicultural coexistence in the mentioning of the physically challenged, aged, and women, as can be seen in the category "People with handicaps, etc." (table 2) and in the fact that the textbooks alternate pictures of girls and boys, and also show Japanese of various ages in the drawings. However, the image of foreigners residing permanently in Japan is missing.

\section{Portrayal of "Foreigners"}

As was described in the previous section, until the $5^{\text {th }}$ grade, which deals with contempo- 
rary Japan, references to foreigners as permanent members of Japanese society is almost nonexistent. Those foreigners that appear, seem to be a result of internationalization (e. g., increase in international transfers, increase in foreigners coming to Japan to study) (table 2). Foreigners are portrayed as requiring pictograms because they cannot read Japanese (2000, $3^{\text {rd }}$ Grade Part 2, 56$7)$, they interact with Japanese children in English as visitors at elementary schools $\left(2000,3^{\text {rd }}\right.$ Grade Part 1,27), the textbook urges students to look at the native countries of exchange students and at foreigners who visit the schools $(2000,4$ th Grade, $1,50,68)$, etc. This concept of coexistence between Japanese and foreigners comes very close to the image of "international exchange," where the nation serves as the point of reference, and the relationship between the Japanese national and foreign national involves little conflict, is horizontal, and equal. Depicted here are foreigners interacting with the Japanese as visitors to Japan. Their life in Japan is not permanent, but temporary. The presence of these foreigners is the result of an internationalizing Japan.

If the Japanese textbooks stopped here, the Japanese social studies textbooks would seem to be implying two things. One, that counter to prevailing stereotypes of the Japanese as disregarding diversity, they do portray diversity, but that diversity is understood as the richness within a relatively mono-ethnic nation-state. The diversity of regions, of lifestyles and occupations of (ethnic) Japanese are portrayed as building blocks of a unified society (what I call the "Japan as Pluralistic" axis). Secondly, the textbooks seem to imply that the challenge of coexistence is above all with nature, and the link with other nations is most notably through commodities that Japanese use in daily life. When coexistence between people of different cultures within Japan is the issue, the foreigners are portrayed as temporary visitors, those who do not speak Japanese fluently and thus require assistance in language (e. g., signs in different languages). The dominant image is that of internationalization. The image of the internationalization of trade resulting in more commodities from other countries in daily life, overlaps with the image of internationalization resulting in more foreign visitors.

Such is the picture portrayed by the textbooks until $5^{\text {th }}$ grade. It is at this point, however, that there seems to be an interesting twist of events. This is what will be dealt with next.

\section{The "Foreigners" Within}

The depiction of "foreigners" shows a distinctive change in the $6^{\text {th }}$ grade part 1 textbook, which is history. As mentioned before, $3-5^{\text {th }}$ grade textbooks focused on the community, geography, and life in Japanese society, and the time period was all contemporary. The first half of $6^{\text {th }}$ grade focuses on history, the latter half comes back to contemporary issues in civics.

In grades 3 to 5 that deal with the present, as was discussed in the preceding section, the "foreigners" portrayed in the textbooks were not those permanently residing in Japan (oldcomers) but "foreigners" that were assumed to come and go. They were foreign nationals, coming to Japan for some reason, engaging in international exchange with Japanese, and then leaving for their own country.

The "foreigners" depicted in the history section, however, are not these "foreigners." The "foreigners" in history appear in the same sections as do, for example, Ainu, ethnic minorities in the Northern parts of Japan, and the outcasts in the feudal caste system (table 3). The "foreigners" that appear in the history section are the Koreans and the Chinese that were invaded or colonized by Japan. "Foreigners" are now linked to human rights and discrimination, and are thus categorized with other historically discriminated-against populations.

The grand narrative of the history portion as it relates to other cultures is as follows: Japan 
Table 3. Sections related to "Discrimination, Human Rights, and Coexistence" in the history section

(From History Portion Grade 6 Part 1)

* Because the history section is quite different from the rest, a different coding process was conducted and four major themes that are relevant to this study were identified;. 1. the transmission of culture, 2 . international relations and war, 3. discrimination, human rights, and coexistence, 4. peace, democracy, and the international community. The following are related content categorized under 3 .

(Discrimination. Human Rights, and Coexistence)

During National Isolation

"Interchange within a Closed Nation" Korea Kingdom of Ryukyu, Ezo, Ainu

Meiji

"Let's Establish a New Government" Equality for all people

"Various Grass-Roots Movements Evolve" Zenkoku Suiheisha; the Great Kanto Earthquake of 1923;

The massacre of Koreans and Chinese, Column: Zenkoku Suiheisha; Movement to win the right of women to vote and improve the status of women; Fusae Ichikawa

has long imported culture from Asia (particularly China and Korea), with which there has been strong ties. Some links with Western countries (importing the technology of firearms, Christianity, etc.) were also present. Discussions of the Ainu, Okinawans, and Koreans are mentioned from a human rights framework. After a series of historical events, such as Hideyoshi's troops to Asia, and national isolation, during which doors were left open to some foreign countries, the "black ships" from the United States signaled a rude awakening to a society that was closed to the rest of the world. Forced open in the face of the military strength of the West, Japan is pushed into unequal treaties with the West and tries very hard to avoid the fate of colonization and domination that most Asian countries faced. Portrayals of how Japan borrowed Western technology and modern systems, and built up its industry and military follow. In between, there is discussion of discrimination within Japan, such as Ainu, the battle for equality on the part of the descendents of the former outcasts (the establishment of an organization Zenkoku Suiheisha), the discrimination against Koreans, and women (table 3). The atomic bombs in Nagasaki and Hiroshima are mentioned with their devastating effects and the message of "no more war." This is followed by a portrayal of Japan's defeat, its efforts to join the international community as a peaceful and democratic nation, and its mission to contribute to the international society.

In short, the history of Japan as it is portrayed in relation to other cultures is that Japan had deep ties with Asia, mostly Korea and China, some ties with the West, followed by a period of war and invasion of Asia, to the present-day Japan as a peaceful democratic nation. Within this grand narrative is situated the story of Asia, the accounts of Koreans and Chinese within Japan who are not "transient" visitors. These "foreigners" are discussed in relation to the other discriminatedagainst populations in Japanese society, which include the Ainu, the descendents of Japan's outcast population under the feudal system, and women. The framework used to understand these "foreigners" is the peaceful coexistence with Asia, human rights, and discrimination, not "internationalization" as was the case until $5^{\text {th }}$ grade.

Why this shift in perspective? Though this is merely a speculation, it might be mentioned that the conflict over Japanese history textbooks has focused mostly on the portrayal of Japanese 
aggression towards Asia (especially China and Korea) during World War II, backed by both political pressure from China and Korea, as well as by human rights groups within Japan. Since this is a heated political topic, and textbooks will be scrutinized as to how they portray China and Korea in the history section, this may be one major reason textbook committees and companies are led to consciously adopt a human rights framework when discussing the history of Asia and Asians within Japan. However, the same type of pressure does not exist in regards to portraying foreigners in contemporary Japan. It might therefore be suggested that the portrayal of foreigners as visitors and as linked to internationalization, is closer to the general image of foreigners in Japanese society.

In any case, a continued examination of textbooks used in the latter half of $6^{\text {th }}$ grade, where the topic once again is contemporary Japanese society, provides more material in understanding the latent mechanisms behind this shift in perspective. The latter part of $6^{\text {th }}$ grade is the section dealing with civics. It describes the system of democratic government, the elections, the balance of power, and other basic knowledge of democracy. At the same time, in discussions of Japan as a welfare state, "foreigners" are mentioned alongside the elderly, people with disabilities, and women. Here the framework is that of welfare, human rights, and striving for a better society. Coexistence with nature is presented in relation to citizens movements, since civil society is a vital sign of a healthy democracy.

If the "foreigners" until $5^{\text {th }}$ grade were temporary visitors as a result of internationalization, and in history were the oldcomers, or were Chinese and Koreans (living in China and Korea) that were the victims of Japan's military aggression, the "foreigners" in the civic section fall into three categories: 1) those that are discussed within the framework of understanding basic human rights, of Japan as a welfare system; 2) peace; and 3)international assistance, exchange, and cooperation with the world.

In the sections that discuss "foreigners" in relation to human rights and welfare, the Ainu and Koreans are mentioned alongside people with handicaps and women (2000, p. 20). Other relevant sections deal with the elderly. In sections dealing with maintaining peace (which sends the message of never repeating war), discussions of Asia, of Chinese returnees from former Manchuria, the fact that Koreans were also the victims of the atomic bomb are mentioned (2000, pp. 247, 2006, p.25).

Such analysis indicates that the temporary foreigners seem to be linked in the minds of the textbook writers with 'internationalization,' as depicted in the $3-5^{\text {th }}$ grade textbooks, while 'human rights/discrimination/welfare' issues are linked with the permanently residing foreigners, and 'peace' is linked with both the image of Asia and the permanently residing foreigners, as seen in both the history and civic sections in $6^{\text {th }}$ grade.

When the theme in the civic section is about "International Assistance, International Exchange, International Cooperation, and Understanding Other Countries," the "foreigners" are again either foreign nationals, or temporary visitors to Japan. The objects of Japanese foreign assistance are developing countries such as Asia and Africa $(2000,22-8)$ and their foreign nationals. There is also a whole unit on "Nations That Have a Deep Link with Japanese Society," which mentions Korea, the U.S., China, and Saudi Arabia (2000 version). This unit describes each country, but the link emphasized is trade (e. g., U. S. jeans, Saudi oil) as in the $3^{\text {rd }}-5^{\text {th }}$ grade textbooks, and although there are portrayals of Korean families, there is no mention of the Koreans in Japan (or the Chinese in Japan). The framework here is nation-to-nation international exchange. The 2006 framework is similar, with the exception that it has included an example of student work investigating 
the Latinos of Japanese descent (2006, p.46). Following the introduction of other nations comes the message to think globally and act locally. Here again, a major theme, especially in the 2000 version, is preserving nature. In addition, international cooperation, world peace, the end of nuclear weapons, etc. are also mentioned. Thus, from the $6^{\text {th }}$ grade civic section, we seem to be observing a hybrid situation where the image of the "foreigner" shifts from those permanently residing in Japan, to the foreign visitors or foreign nationals in other nations, depending on the context of the discussion.

\section{Conclusion}

Japan has often been accused of advancing a monocultural image of itself (Ebuchi, 1994; Kojima, 1999). However, from an examination of elementary social studies textbooks, there is an awareness of a certain kind of diversity and coexistence. The Japan as pluralistic image described in previous pages permeates the textbooks; Japan is portrayed as populated by Japanese in many different occupations, regions, and traditions. Each locality, each occupation is portrayed as equally important. They are pieces which together constitute a pluralistic Japanese nation. There is also an awareness of the coexistence of people and nature, between Japan and other countries, although that coexistence is mainly portrayed through the descriptions of commodities, not people (such as jeans from the United States).

When the focus is the coexistence between the Japanese and people of different cultures, the framework seems to sway depending on, first, whether the discussion is about the past or the present, and second, whether it is about human rights/discrimination/welfare as challenges faced by Japanese society, or whether the discussion is about internationalization.

First of all, when discussing the present, the "foreigners" that appear are mostly assumed to be visitors to Japan. These "foreigners" are linked to an image of the internationalization of Japanese society. The framework adopted here comes very close to the image of international exchange. The relationship is portrayed as horizontal, friendly, and unproblematic. However, when the time period shifts back into the past, the "foreigners" that appear are of a different type. The "foreigners" portrayed here are the Koreans and the Chinese that were victims of Japan's aggression to Asia. When these "foreigners" are portrayed as residing within Japan, they appear in the same sections as other discriminated-against groups in Japanese society. The relationship of these "foreigners" and Japanese society is not unproblematic-there are human rights issues to be solved. Then at the end of sixth grade, "foreigners" again emerge in limited sections. This time they are of different types depending on the context. When the context is that of human rights, welfare, or discrimination, in other words problematic in their relation to Japanese society, the "foreigners" portrayed tend to be those permanently residing in Japan, when the context is internationalization, this seems to be linked to foreign visitors who are assumed to be temporary.

There seems to be little awareness within the textbooks that they are shifting the meaning of being a "foreigner" between the grades, and depending on the context. The shift in how "foreigners" are portrayed sends the message that the "foreigners" within us in contemporary Japan are those who come and go ( $3-5^{\text {th }}$ grade), and the human rights issues that the oldcomer population poses to Japanese society in history is lost until it emerges in fragments in relation to the civic values of human rights at the very end of $6^{\text {th }}$ grade. Compare this with the theme of "coexistence with nature" that appears repeatedly and consistently in all grades and in various contexts. 
The results seem to imply that the image of "foreigners" as permanent residents of Japan emerges mostly in contexts where it is problematic. What seems to be happening is that these "foreigners" are appearing in those areas where there is political pressure or where it is a social problem.

The interpretation of World War II is a major focus of the history wars. Textbook publishers are forced to both portray, and to be sensitive about the portrayal of Koreans and Chinese in history, since it is a highly politicized issue that involves not only groups with different ideologies inside Japan, but foreign countries such as Korea and China as well. At the end of $6^{\text {th }}$ grade in the civic sections dealing with human rights, welfare, and peace, a similar line of thinking seems to link these themes with the permanent residents. "Foreigners" are, at times, added onto a list of historically discriminated-against groups such as the elderly, women, and the handicapped.

However, there is a difference. The elderly, the handicapped, and women are not merely linked to problems facing Japanese society. For example, the elderly are portrayed as both objects of human rights and welfare, and as members of contemporary Japanese society, happily engaging in activities with younger Japanese. They are part of the image of pluralistic Japan that permeates the textbooks - that Japan is made up of many different types of equally valuable Japanese and regions. Since the image of pluralistic Japan is basically mono-ethnic, it is largely missing in the portrayal of permanently residing "foreigners". The "foreigners" that are smiling, and interacting happily with contemporary Japanese in the $3-5^{\text {th }}$ grade textbooks in unproblematic contexts are dominantly the image of foreign guests temporarily visiting Japan. They are outsiders.

The happy faces of the "foreigners" saying hello in English to Japanese children during their visit to Japan in the $3^{\text {rd }}$ grade textbooks somehow do not link with the "foreigners" in the history section who were the victims of WWII. The descendents of the second group of "foreigners" are the "foreigners" that suddenly appear in the $6^{\text {th }}$ grade textbooks under human rights. The link between the two "foreigners" is mostly lost and with it a perspective that might help link the different concepts that seem to be associated with the different types of "foreigners"-in other words, internationalization, human rights, welfare, and peace.

For example, the Indochinese refugees are not only far away people in remote lands requiring donations, but are also residents of Japan. Making children aware of this might help link international issues of war, peace and poverty with issues within. However, the main strategy seems to be to emphasize the incoming of commodities as a means to sensitize children to their link with the outside world. Where the link is not commodities, it is foreign visitors who come and go. The Korean family that appears is not a third generation Korean in Japan, but a Korean family in Korea. Missing is a multi-ethnic image of cultural diversity in Japanese society, and lost with it is the image of diversity as a social asset for Japan, not just something that is problematic.

The challenge, it seems, is in portraying a self-image of Japan that is not only mono-ethnically pluralistic, but also multicultural, where the culturally different are not just without, but within, and where permanent diversity is not only portrayed as a challenge, but as an asset.

\footnotetext{
Notes

1 http://www.nc.uk.net/nc_resources/html/ksland2.shtml, retrieved April 2007.

2 Relevant material is available from the Council of Europe, http://www.coe.int/t/dg4/education/edc/default_EN.asp?, as well as the Center for Civic Education http://www.civiced.org, homepages.

3 Press release, Homusho, 2006 May, http://www.moj.go.jp/PRESS/060530-1.html, retrieved May 2007.
} 


\section{References}

Altbach, Philip G. et al. eds. (1991). Textbooks in American Society: Politics, Policy, and Pedagogy, Albany: State University of New York Press.

Cummings, William K., S. Gopinathan, Y. Tomoda, eds. (1989). The Revival of Values Education in Asia and the West (Comparative and International Education, Vol. 7), New York: Pergamon Press.

Cummings, William K., M. Teresa Tatto and J. Hawkins, eds. (2001). Values Education for Dynamic Societies: Individualism or Collectivism, Hong Kong: The University of Hong Kong.

FitzGerald, France (1979). America Revised, Boston: Little, Brown and Company.

Fujioka, Nobuharu (2005). Atarashi rekishi no kyokasho (shihanbon), revised edition, Tokyo: Fuyosha.

Ienaga Kyokasho Sosho Bengodan eds. (1998). Ienaga kyokasho saiban-32nen ni wataru bengodan katsudo no sokatsu, Tokyo: Nihon Hyoronsha.

Kajita, Takamichi (1998). The challenge of incorporating foreigners in Japan: "Ethnic Japanese" and "sociological Japanese," In M. Weiner and T. Hanami (Eds.), Temporary Workers or Future Citizens?: Japanese and US Migration Policies (pp. 120-147), London: Macmillan Press.

Keizai Sangyosho (Ministry of Economy, Trade and Industry). (2006). Shitsuzenship Sengen (Citizenship Declaration). (Can be obtained from http://www.meti.go.jp/index.html).

Nash, Gary B., C. Crabtree and R. E. Dunn. (1997). History on Trial: Culture Wars and the Teaching of the Past, New York: Alfred A. Knopf.

Nishi, Kanji (2001). Atarashi rekishi kyokasho (shinhanbon), Tokyo: Fuyosha.

Shakaika Kyoiku editing committee (2005, January). Shakaika kyouiku (special edition on citizenship education), No. 547, Tokyo: Meijitosho.

Shinagawaku Kyoiku Iinkai (2006). Shiminka, Tokyo: Kyoiku Shuppan.

Tsuneyoshi, Ryoko (2004, February). The 'new' foreigners and the social reconstruction of difference: The cultural diversification of Japanese education, Comparative Education, 40, 55-81. 